\title{
Frontal-Subcortical Circuits Involved in Reactive Control and Monitoring of Gaze
}

\author{
Katharine N. Thakkar, Fiona M.Z. van den Heiligenberg, Rene S. Kahn, and Sebastiaan F.W. Neggers \\ Brain Center Rudolf Magnus, Department of Psychiatry, University Medical Center Utrecht, 3548 CX Utrecht, The Netherlands
}

\begin{abstract}
Rapid and reactive control of movement is essential in a dynamic environment and is disrupted in several neuropsychiatric disorders. Nonhuman primate neurophysiology studies have made significant contributions to our understanding of how saccadic eye movements can be rapidly inhibited, changed, and monitored. These results highlight a frontostriatal network involved in gaze control and provide a strong basis for understanding how cognitive control of action is implemented in the human brain. The goal of the present study was to bridge human and nonhuman primate studies by investigating reactive control of eye movements during fMRI using a task that has been used in neurophysiology studies: the search-step task. This task requires a speeded response to a visual target (no-step trial). On a minority (40\%) of trials, the target jumps to a new location and participants are instructed to inhibit the initially planned saccade and redirect gaze toward the new location (redirect trial). Compared with no-step trials, greater activation in a frontal oculomotor network, including frontal and supplementary eye fields (SEFs), and the striatum was observed during correctly executed redirect trials. Individual differences in stopping efficiency were related to striatal activation. Further, greater activation in SEF was in a region anterior to that activated during visually guided saccades and scaled positively with error magnitude, suggesting a prominent role in response monitoring. Combined, these data lend new evidence for a role of the striatum in reactive saccade control and further clarify the role of SEF in action inhibition and performance monitoring.
\end{abstract}

Key words: basal ganglia; cognitive control; functional MRI; saccades; search-step task

\section{Introduction}

The ability to make rapid behavioral adjustments is critical in a dynamic environment, and impaired action control is associated with several neuropsychiatric disorders (Chamberlain and Sahakian, 2007). Rapid response inhibition has been investigated with the countermanding paradigm, which requires a fast response unless a subsequent signal is presented instructing participants to inhibit the planned movement. Performance is modeled as a race between competing STOP and GO processes (Logan and Cowan, 1984; Boucher et al., 2007). Using the oculomotor countermanding task, nonhuman primate studies have investigated the cellular basis of reactive inhibition (Schall and Boucher, 2007). Computational modeling and neurophysiology studies have also explored rapid modification of saccade plans using the oculomotor search-step task (Camalier et al., 2007; Murthy et al., 2009; Ramakrishnan et al., 2012). Existing neurophysiology and compu-

Received Feb. 19, 2014; revised May 12, 2014; accepted May 28, 2014.

Author contributions: K.N.T. and S.F.W.N. designed research; K.N.T. and F.M.Z.v.d.H. performed research; K.N.T. and S.F.W.N. contributed unpublished reagents/analytic tools; K.N.T., F.M.Z.v.d.H., and S.F.W.N. analyzed data; K.N.T., R.S.K., and S.F.W.N. wrote the paper.

This work was supported by a Netherlands Organization for Scientific Research Rubicon grant (K.N.T.), Utrecht University (Short-Stay Fellowship to K.N.T. and a Neuroscience and Cognition Grant to S.F.W.N.). We thank Jeffrey Schall, Bram Zandbelt, and Stefan van der Stigchel for their contributions to the experimental design and insightful comments on this manuscript.

The authors declare no competing financial interests.

Correspondence should be addressed to Katharine N. Thakkar, University Medical Center Utrecht, Divisie Hersenen, Afdeling Psychiatrie, Huispost A.01.126, Postbus 85500, 3508 GA Utrecht. E-mail: k.n.thakkar@umcutrecht.nl. D01:10.1523/JNEUROSC1.0732-14.2014

Copyright $\odot 2014$ the authors $\quad 0270-6474 / 14 / 348918-12 \$ 15.00 / 0$ tational modeling work provides an unprecedented basis from which to understand reactive action control in humans.

In neurophysiology studies of saccade countermanding, movement neurons in frontal eye fields (FEFs) and superior colliculus (SC) quickly attenuate their firing rate after the stop cue (Hanes et al., 1998; Paré and Hanes, 2003). In contrast, neurons in medial frontal cortex (MFC) are involved in later evaluative processes (Stuphorn et al., 2000; Ito et al., 2003). Precisely how FEF and SC are modulated during successful stopping is still unclear, but one possibility is through basal ganglia connections. Via the indirect pathway, basal ganglia can inhibit activity in SC directly and in FEF via the thalamus (Hikosaka et al., 2000). In contrast to neurophysiology studies, neuroimaging studies of countermanding in humans nearly always use manual responses and highlight a right-lateralized network including the supplementary motor complex (SMC), particularly the presupplementary motor area (pre-SMA), inferior frontal cortex (IFC), and basal ganglia in inhibition (Chambers et al., 2009; Aron, 2011), although more recent evidence would suggest that IFC plays a general attentional role during stop task performance (for review, see Schall and Godlove, 2012). One explanation for the discrepant findings between human and nonhuman primate studies is effector differences. There is little known about neural correlates of reactive saccade control in humans. Curtis et al. (2005) observed greater fMRI activation in FEF and MFC when saccades were successfully canceled during a countermanding task; however, analyses were restricted to cortical regions. Further, conjunction analyses have indicated that IFC and SMC activation during reactive inhibition are independent of effector (Leung and Cai, 2007; Cai et al., 2014). 
In the present study, we explored cortical and subcortical regions involved in rapid saccade inhibition, redirection, and monitoring in humans using the search-step task for the first time during fMRI. Based on neurophysiology studies, we expected that saccade inhibition and reprogramming would be associated with greater activation in FEF, SC, MFC, thalamus, and the striatum (input node of basal ganglia). We further hypothesized that erroneously noninhibited trials would be associated with greater MFC activation. This study provides an important link between mechanisms of action control in humans and monkeys and a novel evaluation of the frontobasal networks involved in reactive gaze reprogramming in humans.

\section{Materials and Methods}

\section{Participants}

Thirty-eight healthy volunteers participated in this study. One participant was excluded due to excessive motion in the scanner and analyses were conducted on the remaining 37 participants (mean age 29.3 years, range 19-48; 20 females). Handedness was assessed with the Edinburgh Handedness Inventory (mean $=0.67 ; 30$ right-handed, 4 left-handed, 3 ambidextrous). All participants had normal or corrected-to-normal vision and reported no history of neurological or psychiatric illness or history of traumatic brain injury. This study was approved by the University Medical Center Utrecht ethics committee. All participants gave written informed consent according to procedures approved by this committee and were compensated monetarily for their time.

\section{Saccadic search-step task}

Participants performed a variation on the saccadic search-step task (Fig. 1; Camalier et al., 2007; Murthy et al., 2007). The search-step task consisted of three randomly interleaved trial types: no-step (30\% of trials), redirect ( $40 \%$ of trials), and follow (30\% of trials; control condition). Each trial lasted $4 \mathrm{~s}$ and began with a variable fixation period between 1000 and $2000 \mathrm{~ms}$. On no-step and redirect trials, a search array appeared after the fixation period. The eight-element array consisted of a red singleton among green distractors. The array elements subtended $0.7^{\circ}$ of visual angle and were isoluminant and equidistant from the center $\left(9^{\circ}\right.$ of visual angle). On no-step trials, this array remained on the screen for the remainder of the trial. On redirect trials, however, the red target jumped to a new location via an isoluminant color change at some delay after the initial array presentation (target step delay; TSD). On follow trials, the array appeared with two red targets; this array was visible until the end of the trial. On no-step and redirect trials, subjects were instructed to saccade to the red target (T1) as quickly as possible. They were instructed that if the target jumped to a new location (redirect trials), they should try to inhibit the saccade to T1 and look as quickly as possible to the new target location (T2). On follow trials, participants were instructed to look at each red target in succession (the order was irrelevant). Redirect trials in which the subject successfully looked immediately toward T2 were referred to as compensated trials. Redirect trials in which the subject first erroneously made a saccade first to $\mathrm{T} 1$ were referred to as noncompensated trials. Inhibition of the saccade to $\mathrm{T} 1$ becomes more difficult with increasing TSDs (Logan and Cowan, 1984; Camalier et al., 2007). The TSDs were dynamically adjusted with a one-up/one-down tracking procedure, thereby ensuring successful inhibition on $\sim 50 \%$ of the redirect trials. The initial TSD was set at $100 \mathrm{~ms}$ and increased or decreased by $67 \mathrm{~ms}$ when the subject succeeded or failed to inhibit, respectively. TSDs were multiples of the screen refresh rate to minimize timing inaccuracy. To minimize the occurrence of averaging saccades landing midway between $\mathrm{T} 1$ and $\mathrm{T} 2$, target locations were constrained on redirect and follow trials such that there was at least 90 degrees between T1 and T2 (for review, see Van der Stigchel and Nijboer, 2011).

Trials were presented in 45 min experimental sessions consisting of 60 trials. In each session, $610 \mathrm{~s}$ rest blocks displaying only the fixation cross were interleaved as a null condition. Simulations were run before the experiment to determine a trial order in which correlations between the different model regressors was sufficiently low to allow for reliable estimation of parameter estimates. In total, 72 no-step trials, 72 follow trials, and 96 redirect
NO-STEP Trials

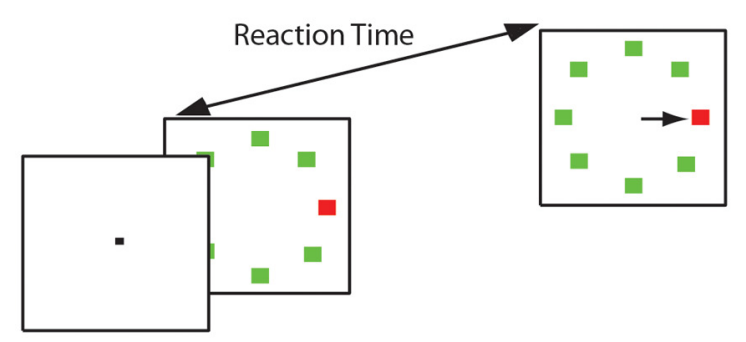

FOLLOW Trials

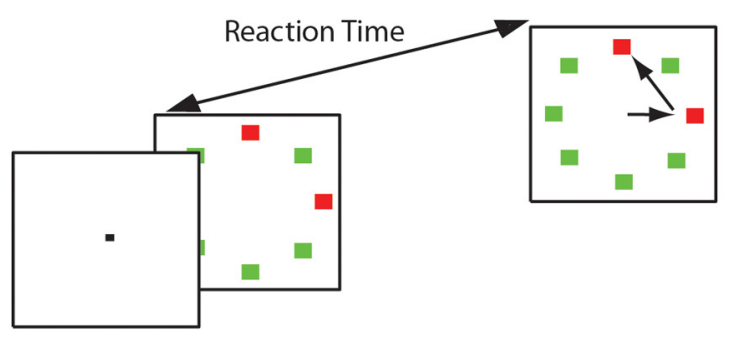

REDIRECT Trials

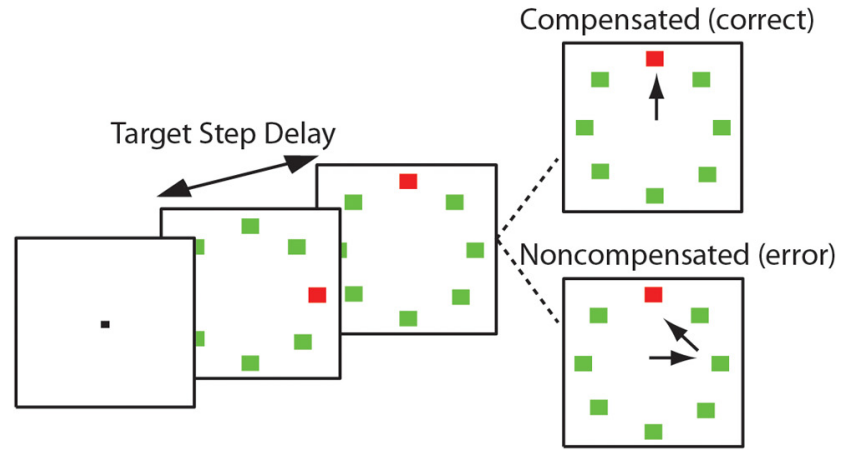

Figure 1. Search-step task. All trials began after a variable fixation length. In no-step trials, a red target was presented among seven green distractors and the participant was instructed to look as quickly as possible to the target. On follow trials, two red targets were presented simultaneously among six green distractors and the participant was instructed to look at each of the targets one after the other (order was irrelevant). On redirect trials, a red target was presented among green distractors. At some delay after the array presentation (TSD), the red target reappeared at a new location in the array and the old location became a distractor. Participants were instructed to inhibit the gaze shift to the old target location and look immediately at the new location of the target. Trials in which participants were successful in looking immediately at the new target location were referred to as compensated, and trials in which the participant erroneously looked first toward the old location of the target were referred to as noncompensated. The probability of correctly compensating becomes more difficult with longer TSDs; therefore, TSD was dynamically altered using a staircase procedure to ensure $\sim 50 \%$ accuracy on redirect trials.

trials were presented. Participants were trained on the search-step task before the fMRI experiment. We instructed participants that speed on the no-step and follow trials was equally as important as successfully inhibiting a saccade to $\mathrm{T} 1$ on redirect trials and that it would not always be possible to inhibit the saccade to T1 on redirect trials. Participants were not explicitly instructed about the relative frequency of trial types.

\section{Stimulus display and eye tracking}

Stimuli were displayed using Presentation software (Neurobehavioral Systems) and presented on an MR-compatible LED screen at the rear of the bore that was viewed by the participant via a mirror on the head coil. Eye movements were recorded during scanning using an MR-compatible 
infrared camera (Nordic Neuro Lab). This system used a video camera mounted to the head coil, with the infrared illumination being provided by LEDs that were also mounted on the head coil. Eye position was sampled at a rate of $60 \mathrm{~Hz}$. Acquisition was controlled by ViewPoint eye-tracking software (Arrington Research). Stimuli presented by Presentation were digitally encoded and relayed to the ViewPoint software as triggers that were inserted into the eye movement recordings. To determine accuracy of redirect trials online for the purpose of the adaptive procedure for adjusting TSD, eye position data from each trial were stored in the memory buffer. After redirect trials, eye position data were drift corrected using the mean eye position in a window from $50 \mathrm{~ms}$ before and after array presentation. A positional criterion was used to determine trial accuracy. If the eye position moved outside of a window spanning $2^{\circ}$ of visual angle around fixation after $100 \mathrm{~ms}$ for at least two samples $(33 \mathrm{~ms})$ and was in the direction of T2, then the trial was classified as compensated and the TSD was increased on the following redirect trial. If the eye position was in the direction of $\mathrm{T} 1$, the trial was classified as noncompensated and the TSD was decreased on the next redirect trial. If the eye position was not in the direction of either T1 or T2 (perhaps due to a blink or noise in the eye trace), the TSD remained the same.

\section{Scoring and analysis of eye movement data}

Eye position data were analyzed offline using a semiautomated MATLAB procedure (The MathWorks). First, eye position data were differentiated

Table 1. Local maxima of brain activation for compensated versus no-step and noncompensated versus follow trials

\begin{tabular}{|c|c|c|c|c|c|c|c|c|}
\hline & \multirow{2}{*}{$\begin{array}{l}\text { Cluster } \\
\text { size }\end{array}$} & \multirow{2}{*}{$\begin{array}{l}\text { Peak } \\
\text { corrected } p\end{array}$} & \multirow{2}{*}{$\begin{array}{l}\text { Peak } \\
T\end{array}$} & \multirow{2}{*}{$\begin{array}{l}\text { Peak } \\
Z\end{array}$} & \multicolumn{3}{|c|}{ Peak MNI coordinates } & \multirow[b]{2}{*}{ Region } \\
\hline & & & & & $x$ & $y$ & $z$ & \\
\hline \multicolumn{9}{|l|}{ Compensated versus no-step } \\
\hline \multirow[t]{39}{*}{ Compensated $>$ no-step } & 97 & 0 & 8.48 & 6.25 & 27 & -63 & 51 & Right superior parietal (IPS) \\
\hline & & 0.002 & 6.74 & 5.39 & 21 & -69 & 45 & Right middle occipital \\
\hline & 238 & 0 & 7.7 & 5.88 & -27 & -81 & 18 & Right middle occipital \\
\hline & & 0 & 7.52 & 5.79 & -30 & -84 & 15 & Left middle occipital \\
\hline & & 0.001 & 7.12 & 5.59 & -36 & -81 & 3 & Left middle occipital \\
\hline & & 0.001 & 6.92 & 5.48 & -18 & -72 & 36 & Left cuneus \\
\hline & & 0.002 & 6.71 & 5.37 & -30 & -78 & -12 & Left fusiform \\
\hline & & 0.002 & 6.65 & 5.33 & -30 & -84 & 6 & Left middle occipital \\
\hline & & 0.01 & 6.2 & 5.08 & -27 & -69 & -9 & Left fusiform \\
\hline & 47 & 0 & 7.61 & 5.84 & 30 & -3 & 51 & Right precentral (FEF) \\
\hline & & 0 & 7.22 & 5.64 & 30 & 3 & 60 & Right middle frontal (FEF) \\
\hline & 67 & 0 & 7.49 & 5.78 & -18 & -63 & 54 & Left superior parietal (IPS) \\
\hline & 107 & 0 & 7.46 & 5.76 & 30 & -81 & 18 & Right middle occipital \\
\hline & & 0 & 7.26 & 5.66 & 36 & -81 & 9 & Right middle occipital \\
\hline & & 0.003 & 6.57 & 5.29 & 48 & -66 & 0 & Right middle temporal \\
\hline & & 0.013 & 6.11 & 5.03 & 27 & -72 & 33 & Right middle occipital \\
\hline & & 0.019 & 5.98 & 4.95 & 33 & -75 & 27 & Right middle occipital \\
\hline & & 0.023 & 5.92 & 4.91 & 27 & -66 & 30 & Right superior occipital \\
\hline & 46 & 0 & 7.33 & 5.7 & 42 & -36 & 48 & Right inferior parietal (IPS) \\
\hline & & 0 & 7.24 & 5.65 & 42 & -36 & 54 & Right inferior parietal (IPS) \\
\hline & 42 & 0.001 & 7.07 & 5.56 & -30 & -48 & 48 & Left inferior parietal (IPS) \\
\hline & & 0.002 & 6.77 & 5.4 & -39 & -42 & 42 & Left inferior parietal (IPS) \\
\hline & 41 & 0.001 & 7.04 & 5.55 & -30 & -3 & 48 & Left precentral (FEF) \\
\hline & & 0.001 & 6.91 & 5.48 & -24 & -6 & 54 & Left superior frontal (FEF) \\
\hline & & 0.006 & 6.38 & 5.18 & -27 & -3 & 60 & Left middle frontal (FEF) \\
\hline & 7 & 0.002 & 6.72 & 5.37 & 63 & -45 & 21 & Right superior temporal (TPJ) \\
\hline & 10 & 0.003 & 6.56 & 5.29 & 33 & 21 & 6 & Right insula \\
\hline & 16 & 0.004 & 6.5 & 5.25 & 36 & -66 & -12 & Right fusiform \\
\hline & 7 & 0.004 & 6.49 & 5.25 & -54 & 3 & 42 & Left precentral \\
\hline & 39 & 0.004 & 6.49 & 5.25 & 51 & 12 & 30 & Right IFC \\
\hline & & 0.004 & 6.45 & 5.23 & 48 & 9 & 27 & Right IFC \\
\hline & & 0.005 & 6.38 & 5.19 & 42 & 15 & 30 & Right IFC \\
\hline & 6 & 0.007 & 6.28 & 5.13 & -33 & 21 & 6 & Left insula \\
\hline & 1 & 0.031 & 5.82 & 4.86 & -39 & -60 & -12 & Left fusiform \\
\hline & 1 & 0.035 & 5.78 & 4.83 & 30 & -72 & -9 & Right fusiform \\
\hline & 1 & 0.042 & 5.72 & 4.79 & -33 & 6 & 51 & Left middle frontal (FEF) \\
\hline & 1 & 0.045 & 5.69 & 4.78 & 9 & 18 & 54 & Right SMA (pre-SEF) \\
\hline & 1 & 0.048 & 5.68 & 4.77 & 3 & 15 & 51 & Right SMA (pre-SEF) \\
\hline & 1 & 0.048 & 5.68 & 4.77 & 9 & 27 & 39 & Right midcingulum (ACC) \\
\hline \multirow{4}{*}{ No-step > compensated } & 14 & 0.001 & 7.15 & 5.6 & -51 & -72 & 33 & Left angular \\
\hline & 6 & 0.006 & 6.37 & 5.18 & -9 & 51 & 39 & Left medial superior frontal \\
\hline & 1 & 0.033 & 5.8 & 4.84 & -39 & 30 & -18 & Left inferior orbital frontal \\
\hline & 1 & 0.045 & 5.7 & 4.78 & -18 & 36 & 48 & Left superior frontal \\
\hline \multicolumn{9}{|l|}{ Noncompensated versus follow } \\
\hline \multirow[t]{9}{*}{ Noncompensated $>$ follow } & 20 & 0.001 & 7.16 & 5.61 & -60 & -48 & 15 & Left superior temporal (TPJ) \\
\hline & 3 & 0.005 & 6.42 & 5.21 & 36 & 18 & -12 & Right insula \\
\hline & 5 & 0.01 & 6.2 & 5.08 & 45 & 15 & -6 & Right insula \\
\hline & 4 & 0.016 & 6.04 & 4.99 & 51 & -42 & 18 & Right superior temporal (TPJ) \\
\hline & 4 & 0.018 & 5.99 & 4.96 & 63 & -48 & 30 & Right supramarginal (TPJ) \\
\hline & 1 & 0.022 & 5.93 & 4.92 & -39 & -69 & 6 & Left middle occipital \\
\hline & 1 & 0.042 & 5.72 & 4.79 & 60 & -39 & 39 & Right supramarginal (TPJ) \\
\hline & 2 & 0.042 & 5.72 & 4.79 & 54 & -45 & 9 & Right middle temporal \\
\hline & 1 & 0.044 & 5.7 & 4.78 & 51 & 18 & 6 & Right IFC \\
\hline
\end{tabular}


to obtain a velocity signal and then filtered with a fifth-order Butterworth filter ( $40 \mathrm{~Hz}$ cutoff). Then, saccade onsets were determined automatically using liberal velocity criteria. After this automated procedure, erroneously marked saccades (e.g., camera noise, head movements, blinks, etc.) were removed manually. Verification of saccade onsets was performed blind to the experimental condition. Trials in which saccades were produced $<100 \mathrm{~ms}$ after array onset were excluded from further analysis. Directional accuracy of saccades relative to the required response was determined using an automated procedure. Saccade latency on no-step, noncompensated, and follow trials was calculated as the onset of the saccade relative to array onset. Latency of compensated saccades was calculated as the onset of the saccade relative to T2 onset.

Behavioral performance was evaluated through measurements of saccadic RT on no-step and noncompensated trials and TSD. At each TSD, the proportion of trials in which a participant successfully made a saccade immediately to $\mathrm{T} 2$ was quantified. The proportion of compensated trials at each delay is referred to as the compensation function. Performance in the search-step task can be accounted for by a mathematical model that assumes a race between independent processes that generate (GO1) and inhibit (STOP) the movement to the initial target location (Logan and Cowan, 1984; Camalier et al., 2007). The response to T1 is executed if the GO1 process finishes first and inhibited if the STOP process finishes first. The latency of the GO process can be measured directly from the observable reaction times (RTs), but the latency of the STOP process is estimated. The independent race model provides an estimate of the time needed to respond to the target step and cancel the saccade to T1, referred to as the target step RT (TSRT). This is an analogous measure to stop-signal RT (SSRT) in the standard countermanding paradigm. TSRT was calculated using the integration method (Logan and Cowan, 1984; Congdon et al., 2012; Verbruggen et al., 2013). RTs on no-step trials were sorted in ascending order and the RT corresponding to the proportion of noncompensated trials was selected. The mean TSD was then subtracted from this RT.

Repeated-measures ANOVA was used to compare differences in RT for the four trial types. Because of eye tracker malfunction, eye data from two subjects were too noisy to allow for precise saccade onset and offset detection, so these two subjects were excluded only from latency and amplitude analyses.

\section{Image acquisition}

The experiment was performed on a 3.0 T Achieva MRI scanner (Philips Medical Systems) at the University Medical Center Utrecht. Images were acquired using an eight-channel sensitivity-encoding (SENSE) parallel imaging head coil. Whole-brain $\mathrm{T} 2{ }^{\star}$-weighted echo planar images with bloodoxygen level-dependent (BOLD) contrast ( 4 sessions; 152 volumes; 35 slices per volume; interleaved acquisition; $\mathrm{TR}=2 \mathrm{~s}$; $\mathrm{TE}=35 \mathrm{~ms}$; field of view $=$ $256 \times 256 \times 120 \mathrm{~mm}$; flip angle $=70^{\circ} ; 96 \times 96 \times 35$ matrix; voxel size $=$ $2.67 \times 2.67 \times 3.42$; SENSE factor, 2.4 anterior-posterior) oriented in a transverse plane were acquired. The first six images were discarded to allow for T1 equilibration effects. A whole-brain three-dimensional fast-field echo $\mathrm{T} 1$-weighted scan $\left(200\right.$ slices; $\mathrm{TR}=10 \mathrm{~ms} ; \mathrm{TE}=4.6 \mathrm{~ms}$; flip angle $=8^{\circ}$; field of view, $240 \times 240 \times 160 \mathrm{~mm}$; voxel size: $0.75 \times 0.8 \times 0.75 \mathrm{~mm}$ ) was acquired for within-subject registration purposes.

To remove cardiac and respiratory pulsality effects that contaminate BOLD fMRI time series, cardiac signals and respiration were measured using equipment built into the Philips Achieva scanner. Cardiac signals were measured at $500 \mathrm{~Hz}$ with ECG electrodes and respiration was recorded at $500 \mathrm{~Hz}$ using a band wrapped around the midsection.

\section{Data analysis}

Preprocessing. Functional imaging data were preprocessed and analyzed using SPM8 (http://www.fil.ion.ucl.ac.uk/spm/software/spm8) and MATLAB. First, the raw fMRI data were preprocessed spatially. Images were realigned to correct for head motion in the scanner using rigid body transformations and a mean functional image was created. Next, the data were temporally interpolated per slice to correct for the individual timing differences in slice acquisition such that the signal of each slice was interpolated to the time of acquisition of the middle slice. The anatomical image was coregistered to the mean functional image using the normalized mutual information criteria method. Segmentation and normaliza- tion of the anatomical image into Montreal Neurological Institute (MNI) space was achieved using a unified segmentation method (Ashburner and Friston, 2005) The same normalization parameters were applied to the function scans, which were in register with the anatomical images. Finally, the fMRI images were spatially smoothed with a Gaussian kernel with an FWHM of $6 \mathrm{~mm}$.

Statistical analyses. Statistical analysis was performed within the framework of the general linear model (GLM) and followed a two-level procedure. First-level statistical analysis involved modeling of no-step, follow, compensated, and noncompensated trials. According to race model logic, compensated trials are sampled from the slowest part of the RT distribution; essentially, these are the trials for which the preparation of the saccade to T1 had not progressed far enough to escape inhibition. Therefore, no-step RTs were split based on the percentile corresponding to the proportion of noncompensated trials and no-step trials were divided into slow and fast. These no-step-slow and no-step-fast trials were modeled separately. Compensated trials were compared with these latency-matched no-step-slow trials; such latency matching is common practice in neurophysiology (Hanes et al., 1998; Murthy et al., 2009), electrophysiology (Reinhart et al., 2012), and human fMRI (Aron and Poldrack, 2006) studies. Rest (fixation) trials were not explicitly modeled and therefore constituted an implicit baseline. Regressors were created by convolving delta functions coding for array onset with a canonical hemodynamic response function. Twenty nuisance regressors were added to model cardiac and respiratory pulsatility using the RETROICOR method with fifth-order Fourier expansions (Glover et al., 2000). Physiological non-neuronal rhythms are known to have a robust effect on the BOLD signal, especially in midbrain and basal ganglia areas, due to, among other things, the arterial circle of Willis vasculature. Modeling such rhythms as covariates using RETROICOR increases sensitivity to neuronal activation of interest. Temporal autocorrelation in the fMRI data was modeled using autoregressive modeling of the first order by prewhitening the GLM equation. Data were also high-pass filtered during prewhitening with a cutoff cycle length of $70 \mathrm{~s}$.

In determining our contrasts of interest, we were careful to match conditions on the number of task-related saccades produced per trial. Therefore, to examine activation related to inhibition and reprogramming, contrast images were generated for the comparison of compensated versus no-step-slow. In both of these trials, only one saccade was produced; however, compensated trials required the inhibition and redirection of the planned saccade to $\mathrm{T} 1$, so activation in this contrast likely reflects these processes. To examine activation related to error processing, contrast images were generated for the comparison of noncompensated versus follow trials. In both of these trials, two saccades were produced; however, in noncompensated trials, the first saccade was committed in error. Finally, to investigate activity related to successful versus unsuccessful inhibition, contrast images were generated for compensated versus noncompensated trials, taking into account that these two trial types differed in the number of saccades produced when interpreting putative

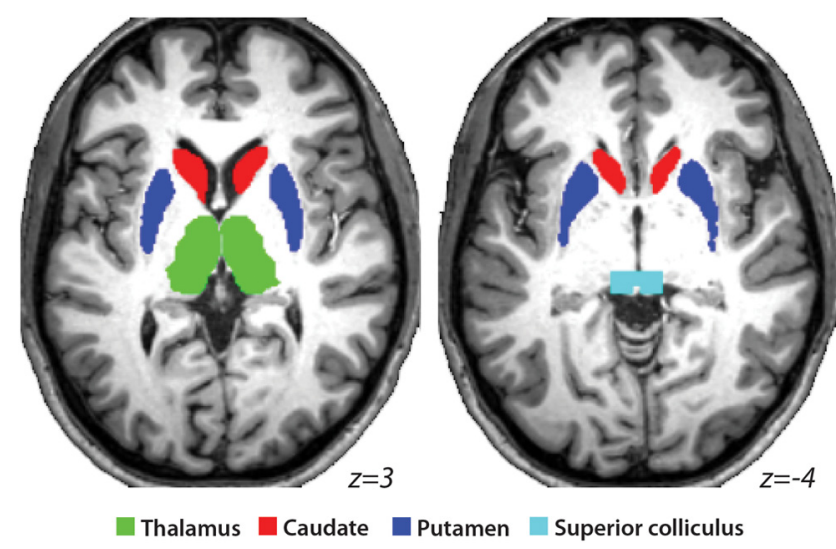

Figure 2. Subcortical ROls displayed on a representative single-subject MNI-normalized brain. 
differences. First-level contrast images were analyzed in a whole-brain second-level randomeffects analysis using one-sample $t$ tests. Voxel thresholds for all group-level contrasts were set to $p<0.05$ familywise error corrected (FWE) for multiple comparisons using a gray matter mask. Coordinates and statistical values for peak voxels within significant clusters are reported in Table 1. Reported local maxima correspond to MNI space.

Because the MR signal becomes weaker with increased distance from the head coil, we also conducted ROI analyses in four subcortical ROIs bilaterally: thalamus, caudate, putamen, and superior colliculus. These ROIs were manually delineated on the averaged normalized high-resolution T1 image from our sample (Fig. 2). Because normalization procedures are very effective in subcortical regions, each of these structures was clearly visible. Local percentage signal change was extracted from each of these eight regions for each trial type. Paired $t$ tests were used to compare activation within regions across conditions and the Bonferroni-Holm procedure (Holm, 1979) was used to correct for testing of multiple ROIs.

Finally, we examined how individual differences in inhibition efficiency, indexed by TSRT, related to brain activation. First, whole-brain correlations were examined between TSRT and activation that was greater for compensated than no-step trials. For this analysis, we restricted our search space to those regions that showed greater activation for compensated than no-step trials at an uncorrected threshold of $p<$ 0.0001 . Voxel threshold was set to $p<0.05$ FWE corrected for multiple comparisons within the set of functionally defined regions. Second, we correlated TSRT with the difference in percent signal change between compensated and no-step trials within those subcortical ROIs that showed greater activation in that contrast.

\section{Results}

Behavioral data

The dynamic tracking procedure was successful and the mean proportion of noncompensated trials was $47 \%$. For each subject, the compensation functions were generally increasing, indicating poorer inhibition ability with longer TSDs (Fig. $3 a$ ). The effect of trial type (no-step, follow, compensated, or noncompensated) on first saccade RT (Fig. $3 b$ ) was assessed with a repeated-measures ANOVA. There was a significant effect of trial type $\left(F_{(3,102)}=\right.$ $30.0, p<0.0001)$. Pairwise comparisons, Bonferroni corrected for the six comparisons, indicated that noncompensated trials were faster than no-step trials $\left(t_{(34)}=4.5\right.$, corrected $\left.p<0.0001\right)$, which is consistent with race model logic. In addition, follow trials were slower than no-step $\left(t_{(34)}=6.6\right.$, corrected $\left.p<0.0001\right)$, compensated $\left(t_{(34)}=7.8, p<0.0001\right)$, and noncompensated $\left(t_{(34)}=9.2, p<0.0001\right)$ trials. RT differences between compensated trials and both no-step and noncompensated trials were not significant. Mean TSRT was $165 \mathrm{~ms}$ (SD = $29 \mathrm{~ms}$ ), which is consistent with previous studies with healthy human subjects (Camalier et al., 2007) and indicates that the scanner environment and inclusion of follow trials did not markedly alter performance in this task.

\section{fMRI data}

\section{Compensated versus no-step}

Because there was no difference in activation between no-stepfast and no-step-slow trials, even at a FWE-corrected $p<0.1$, data were collapsed across all no-step trials. Compared with fixation, no-step trials activated an expected network of occipital and oculomotor regions, including bilateral FEF, bilateral intraparietal sulcus (IPS), and left SEF (Fig. 4a). In our subcortical ROIs, only left putamen showed a greater response on no-step trials versus fixation (Fig. $6 ; t_{(36)}=3.0$, corrected $p=0.02$, 1-tailed). Although, based on neurophysiology studies of the striatum, caudate is typically considered to play a larger role in the oculomotor system and putamen a larger role in the skeletomotor system (Alexander et al., 1990), our findings are consistent with recent work from both human fMRI showing a predominant role of the putamen in visually guided saccades (Dejardin et al., 1998; Krebs et al., 2010; Neggers et al., 2012). Compensated trials activated a similar network of occipital and oculomotor regions, including bilateral FEF, bilateral IPS, and bilateral SEF (Fig. 4b). Notably, compensated trials activated a larger region of SEF, extending more anteriorly and into anterior cingulate cortex (ACC). We refer to this region as pre-SEF. This pre-SEF region was not activated on no-step trials (Fig. 5). In addition, activation of right IFC was observed on compensated trials. ROI analyses yielded significant activation for compensated trials relative to fixation in bilateral SC (left: $t_{(36)}=3.0$, corrected $p=0.02$, 1-tailed; right: $t_{(36)}=2.8$, corrected $p=0.03,1$-tailed) and left putamen $\left(t_{(36)}=2.6\right.$, corrected $p=0.04,1$-tailed $)$.

Direct comparison of compensated and no-step trials revealed greater activation in bilateral FEF, bilateral IPS, right SEF extending into ACC, and right IFC, as well as bilateral occipitotemporal regions and insula (Fig. 4c). ROI analyses (Fig. 6) revealed greater activation for compensated than no-step trials in bilateral SC (left: $t_{(36)}=3.4$, corrected $p=0.03,2$-tailed; right: $t_{(36)}=3.0$, corrected $p=0.01,2$-tailed), bilateral thalamus (left: $t_{(36)}=2.8$, corrected $p=0.04,2$-tailed; right: $t_{(36)}=3.4$, corrected $p=0.01$, 2 -tailed), and left CN $\left(t_{(36)}=2.6\right.$, corrected $p=0.04$, 2-tailed). Note that the low, albeit significant, average signal in our subcortical ROIs is due to averaging over fairly large regions.

To determine whether the efficiency of inhibition varied over subjects as a function of activation within these brain regions that showed greater activation for compensated than no-step saccades, we performed a correlational analysis with TSRT across individuals. Whole-brain analysis revealed that greater activation in bilateral occipital and left occipitoparietal cortex was correlated with faster TSRT (Fig. 7a). This finding is perhaps not so surprising. Modeling work indicates that visually processing the stop/step signal comprises a large part of SSRT/TSRT (Boucher et al., 2007a; Salinas and Stanford, 2013). To the extent that greater visual cortex activation on compensated trials represents process- 


\section{a No-step > Fixation}

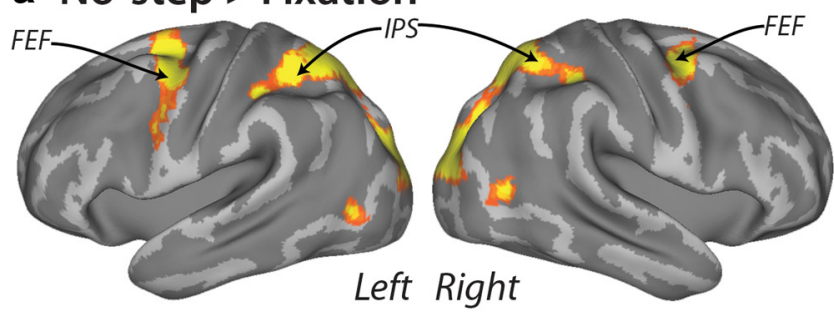

\section{b Compensated > Fixation}
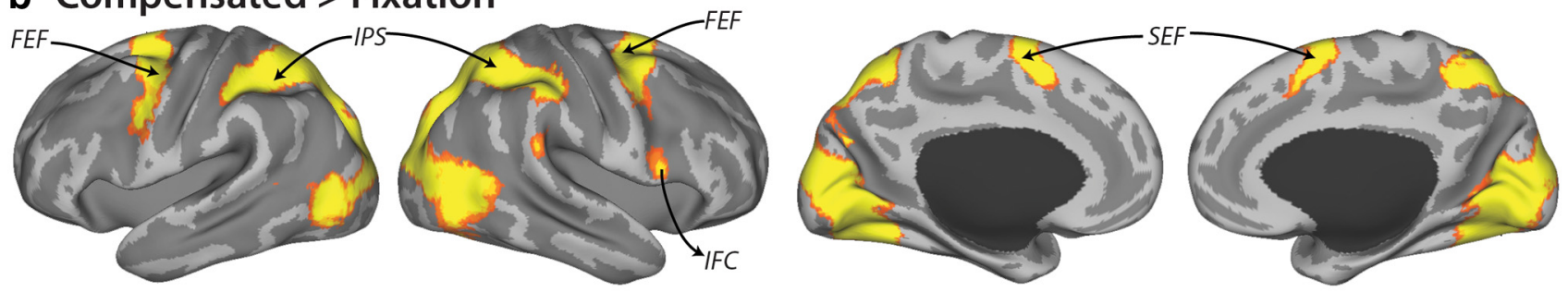

\section{c Compensated $>$ No-step}
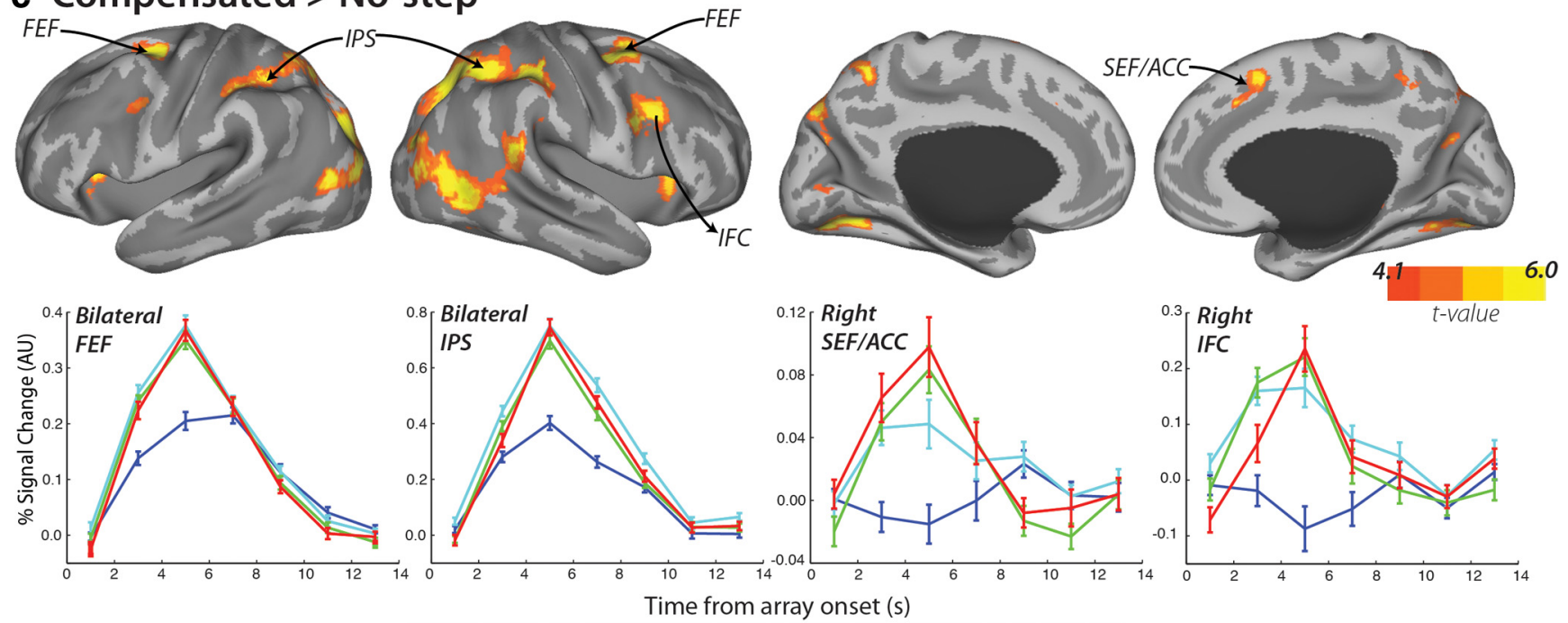

Time from array onset (s)

-No-step Compensated - Noncompensated -Follow

Figure 4. BOLD activation that is greater for compensated than no-step trials. Cortical activation that is greater for no-step trials versus fixation $(\boldsymbol{a})$, compensated trials versus fixation $(\boldsymbol{b})$, and compensated versus no-step trials (c) was rendered onto an MNI-normalized inflated surface. Activation is displayed at an uncorrected $p<0.0001$. Clusters that met significance at a FWE-corrected $p<0.05$ are displayed in Table 1. Group event-related time courses (bottom) were calculated for each trial type within a $3 \mathrm{~mm}$ sphere centered on the maximally activated voxel in FEFs, IPS, right SEFs extending into ACC (SEF/ACC), and right IFC. For FEF and IPS, time courses were averaged across right and left hemispheres. Error bars indicate SEM.

ing of the target jump, these data suggest that more effective processing of the target step leads to faster inhibition of the initial saccade plan. Within our subcortical ROIs, only caudate activation ( signal change averaged over entire ROI) was correlated with faster TSRT (Fig. 7b). This relationship reached significance bilaterally after exclusion of a bivariate outlier (outlier included: left: $r=-0.13, p=0.44$; right: $r=-0.37, p=0.03$; outlier excluded: left: $r=-0.34, p=0.05$, right: $r=-0.43, p=0.01$ ).

Compensated versus noncompensated

To examine putative activation related to successful versus unsuccessful inhibition, we compared compensated (correct redirect) to noncompensated (incorrect redirect) trials. Noncompensated trials activated a similar network of occipital, parietal, and frontal regions as compensated trials, including bilateral FEF, IPS, and SEF, as well as right IFC (Figs. 4b, 8a). In addition, ROI analyses (Fig. 6) revealed additional activation in bilateral SC (left: $t_{(36)}=4.3$, corrected $p=$ $0.0007,1$-tailed; right: $t_{(36)}=4.8$, corrected $\left.p=0.0001\right)$. There were no regions of greater activation for compensated trials than noncompensated trials at the whole-brain level, even at an FWEcorrected threshold of $p<0.1$, nor in any of the ROIs. Noncompensated trials showed greater activation in occipital areas, most likely due to the second corrective saccade.

Equivalent activation for correctly compensated saccades and incorrectly noncompensated trials is consistent with a previous study of oculomotor stopping (Curtis et al., 2005) and there are several possible reasons for a failure to discriminate these two trial types in the BOLD response. First, compensated and noncompensated trials were not matched on the number of saccades executed because noncompensated trials were almost always followed by a corrective saccade to T2. Therefore, potential differences in activation related to inhibition and reprogramming might have been washed out by activation related to the second, corrective saccade. Second, a STOP process was likely triggered on noncompensated trials, but simply did not win the race, re- 


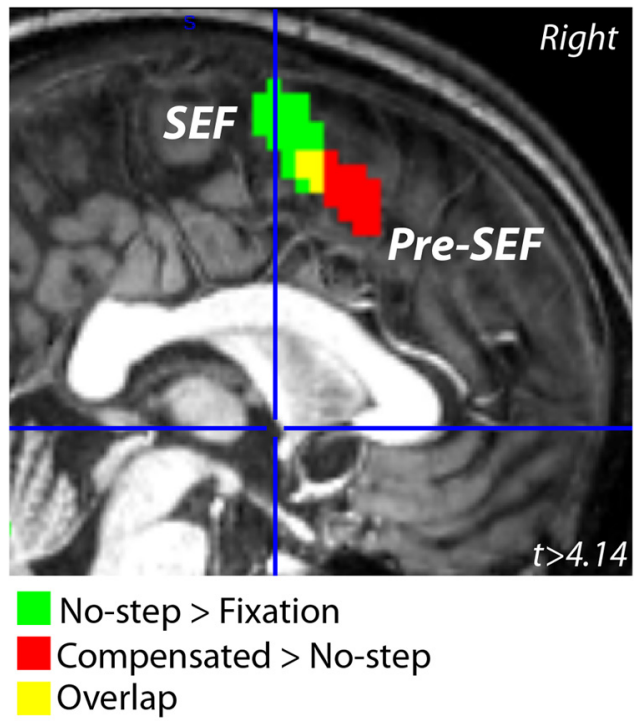

Figure 5. Functional subdivisions of SEFs. SEF activation that was greater on compensated than no-step trials (red) was anterior to the region of SEF that showed activation on no-step trials relative to fixation (green). Overlap between these two clusters of activation is displayed in yellow. Activations are displayed at an uncorrected $p<0.0001$ on a representative singlesubject MNI-normalized brain.

sulting in a largely overlapping network of activation. The difference between brain activity related to successfully inhibited saccades versus unsuccessfully noncompensated saccades might be more related to the timing than the magnitude of activation, which is not captured by the sluggish BOLD signal.

\section{Noncompensated versus follow}

To investigate error-related activation, we compared noncompensated trials with follow trials. Each of these trial types comprised two task-saccades, but follow trials were executed correctly and noncompensated trials were erroneous redirect trials. As expected, follow trials activated a network of occipital and frontoparietal regions, including bilateral FEF, SEF, and IPS (Fig. 8b). ROI analyses (Fig. 6) indicated greater activation for follow trials versus fixation in bilateral putamen (left: $t_{(36)}=5.3$, corrected $p<0.0001$, 1-tailed; right: $t_{(36)}=3.8$, corrected $p=0.004$, 1 -tailed) and bilateral SC (left: $t_{(36)}=3.4$, corrected $p=0.005$, 1-tailed; right: $t_{(36)}=3.3$, corrected $p=0.006,1$-tailed). Direct comparison showed greater activation on noncompensated trials in bilateral temporoparietal junction (TPJ), right insula, and right IFC, as well as left occipitoparietal cortex (Fig. 8c). There were no regions at the whole-brain level that showed greater activation for follow trials. Subcortically, there were no regions of greater activation for noncompensated than follow trials; however, there was greater activation in putamen on follow trials compared with noncompensated trials, which only survived correction for multiple comparisons in the left hemisphere $\left(t_{(36)}=\right.$ $3.3, p=0.02,2$-tailed).

Given the extensive literature documenting the role of MFC in error processing, we were rather surprised by the absence of greater activation in this region on noncompensated trials compared with follow trials. We therefore explored noncompensated trials in more detail by examining the dynamics of the error saccade and how these error saccade dynamics might relate to MFC activation. A previous search-step study reported the occurrence of partial errors on noncompensated trials, in which the error saccade was interrupted by the corrective saccade to T2 (Camalier et al., 2007). This variability in error saccade endpoint suggests

\section{a Caudate}

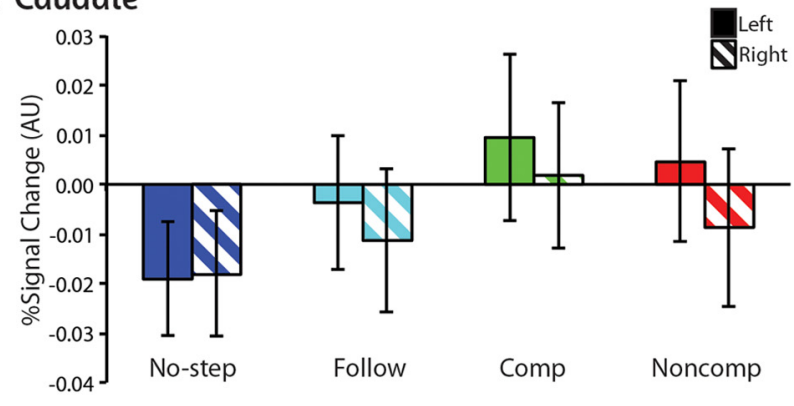

b Putamen

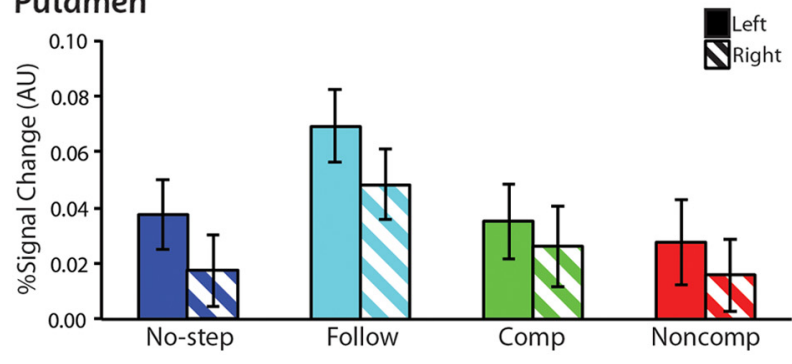

C Thalamus

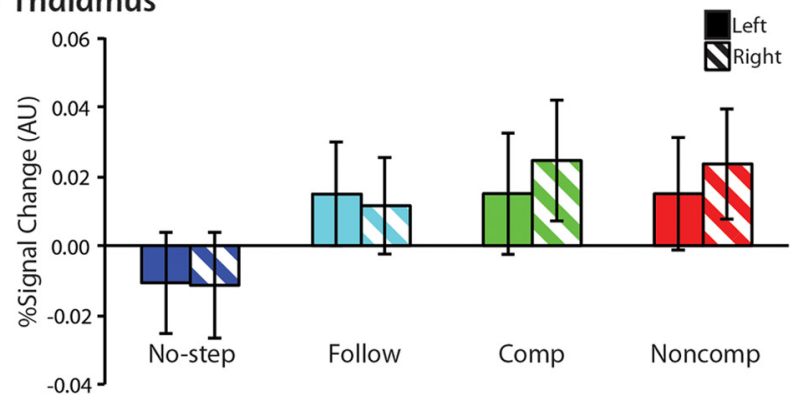

\section{d Superior colliculus}

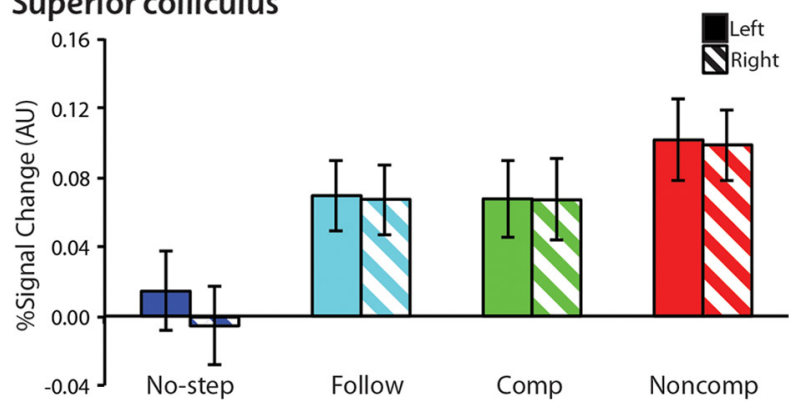

Figure 6. Percent signal change in subcortical ROIs. Mean percent signal change was calculated for each of the four trial types in four anatomically defined subcortical ROls: caudate (a), putamen ( $\boldsymbol{b})$, thalamus (c), and superior colliculus ( $\boldsymbol{d}$ ) in left (solid bars) and right (striped bars) hemispheres. Percent signal change was averaged across participants. Error bars indicate SEM.

that the STOP process can have varying degrees of influence on noncompensated trials and that errors can differ quantitatively, essentially in how wrong they are. In a post hoc analysis, we investigated whether the magnitude of the error, as measured by saccade amplitude, influences MFC activation.

We fit a separate model to our fMRI data that included amplitude as a parametric modulator of activation on all four trial types. In such parametric modulation analysis, we investigate whether the hemodynamic response scales positively or negatively with a given continuous predictor. We expected that MFC activation would increase as a function of error amplitude on noncompensated trials. To ensure that any putative relationship 
a
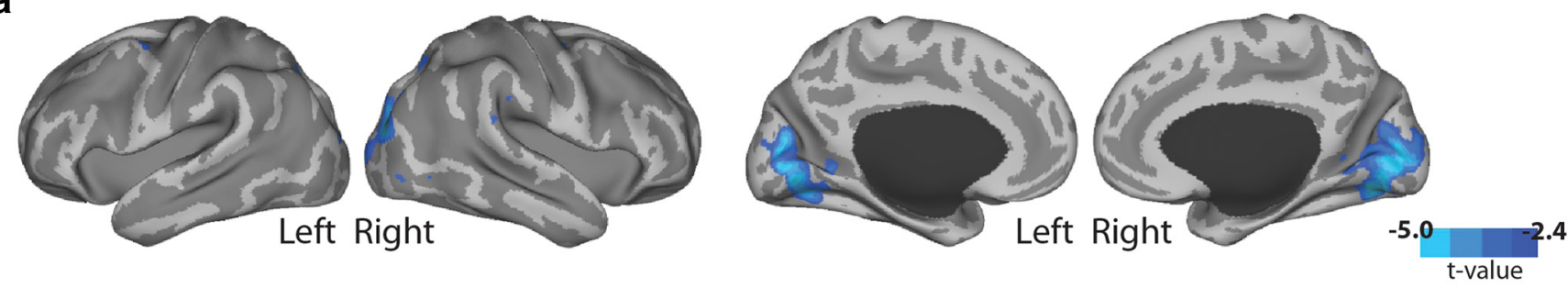

b
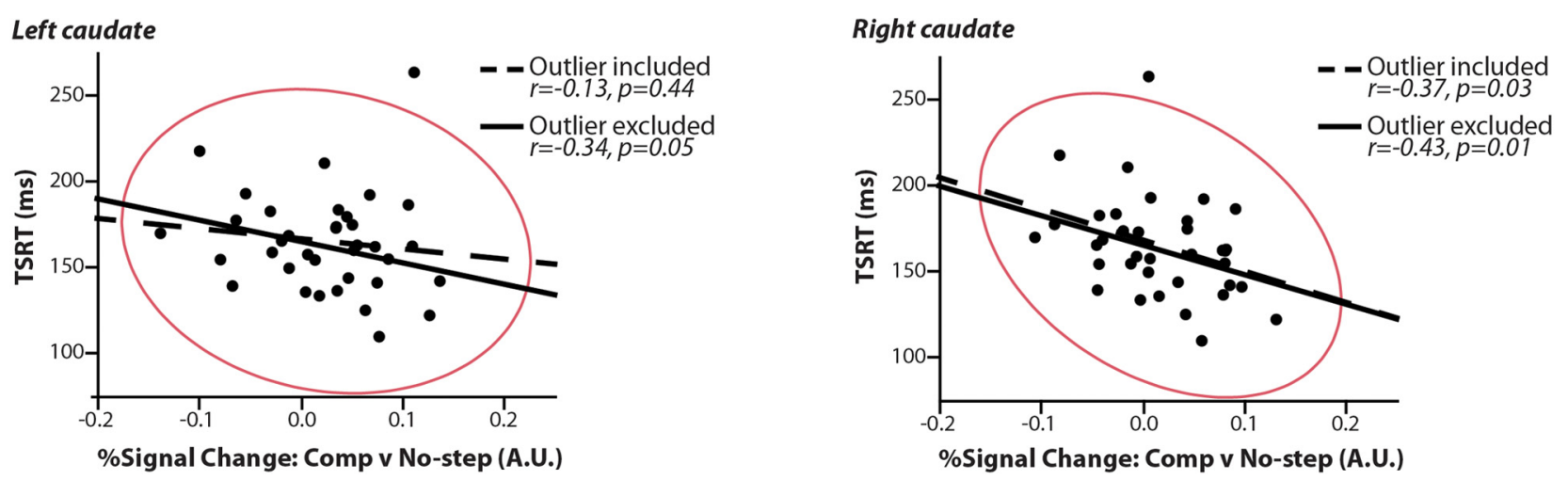

Figure 7. Correlation between BOLD activation and TSRT. $\boldsymbol{a}$, Cortical regions in which individual activation differences in the compensated $>$ no-step contrast trials were negatively related to TSRT are displayed in cool colors at an uncorrected $p<0.01 . \boldsymbol{b}$, Relationship between greater percent signal change in compensated versus no-step trials and TSRT in the anatomically defined caudate. The red ellipse represents a 95\% density ellipse around the mass of points in both the right and left hemispheres, and correlation coefficients ( $r$ ) are displayed with and without the outlier included. In both visual cortex and caudate, greater activation on compensated versus no-step trials was related to faster stopping.

between error saccade amplitude and MFC activation was not related to more trivial aspects of movement dynamics, we also investigated whether MFC activation varied as a function of saccade amplitude on no-step, compensated, and follow trials. For this parametric analysis, we restricted our search space to the region of MFC, defined using the Automated Anatomical Labeling atlas (Tzourio-Mazoyer et al., 2002), which showed greater activation for noncompensated trials relative to fixation at an uncorrected threshold of $p<0.01$. Voxel thresholds for these parametric contrasts were set to $p<0.05$ FWE corrected for multiple comparisons within this functionally defined region of MFC.

Behaviorally, noncompensated saccades were shorter than the other four trial types, suggesting that, on average, the error was interrupted by a corrective response to the new target location. This was supported by a repeated-measures ANOVA conducted on first saccade amplitude with trial type as within-subject factor. There was a significant effect of trial type (Fig. $9 a ; F_{(3,34)}=35.5$, $p<0.0001$ ). Pairwise comparisons were Bonferroni-Holm corrected for the six post hoc tests and indicated that noncompensated saccades were significantly shorter than no-step $\left(t_{(34)}=8.3\right.$, corrected $p<0.0001)$, follow $\left(t_{(34)}=5.8\right.$, corrected $\left.p<0.0001\right)$, and compensated $\left(t_{(34)}=9.1\right.$, corrected $\left.p<0.0001\right)$ trials. In addition, compensated saccades were larger than both no-step $t_{(34)}=3.4$, corrected $\left.p=0.003\right)$ and follow $\left(t_{(34)}=3.9\right.$, corrected $p=0.001)$ trials. Results of the parametric analysis on BOLD data were consistent with our hypothesis, and we observed that activation in MFC, namely SEF, was related to larger errors on noncompensated trials (Fig. 9b,c). This parametric effect only reached significance in the right hemisphere. Importantly, there was no relationship between saccade amplitude and MFC activation on no-step, follow, or compensated trials (Fig. 9c). Therefore, error-related brain activation in MFC scaled with the magnitude of the error.

\section{Discussion}

In the present study, we observed a corticobasal network involved in controlling and monitoring saccades. To our knowledge, this is the first fMRI study of reactive changes to saccade plans, and our results make novel contributions regarding the role of the striatum and functional subdivisions of SEF involved in saccade control.

\section{Inhibiting and changing a response}

We compared activation between compensated and no-step trials. In interpreting the significance of greater compensated trial activation, we consider several possibilities. Modeling work suggests that compensated trials involve inhibiting the initial response and simultaneously programming the final response (Camalier et al., 2007; Ramakrishnan et al., 2012). Accordingly, greater compensated trial activation could reflect inhibition of the first saccade. In contrast to no-step trials, however, compensated trials also involve visuomotor processes associated with a saccade to both T1 and T2. Therefore, target selection and subthreshold motor processes associated with the suppressed response could result in greater activation. Alternatively, greater activation might arise from conflict between incompatible responses to T1 and T2. Finally, greater activation could reflect attentional processes associated with the target jump. To disentangle these hypotheses, we considered the activation pattern on no-step and compensated trials.

Some regions, including bilateral FEF and IPS, show significant activation on no-step trials and greater activation on compensated trials, which is consistent with a previous saccade countermanding fMRI study (Curtis et al., 2005) and with neurophysiology data showing modulation of FEF neurons when saccades are cancelled (Hanes et al., 1998). Therefore, greater FEF and IPS activation may relate to inhibiting the initial saccade; 
a Noncompensated $>$ Fixation

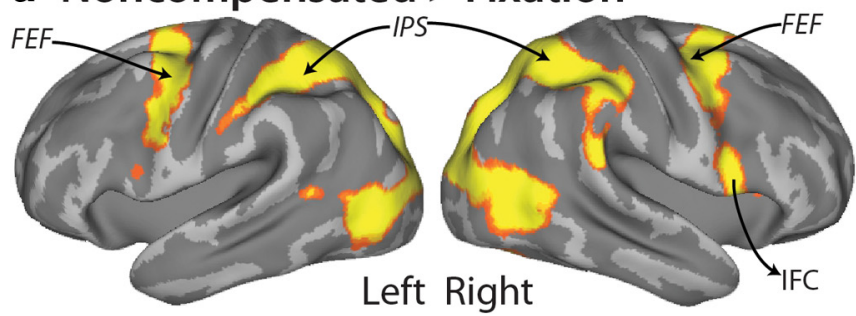

\section{b Follow $>$ Fixation}

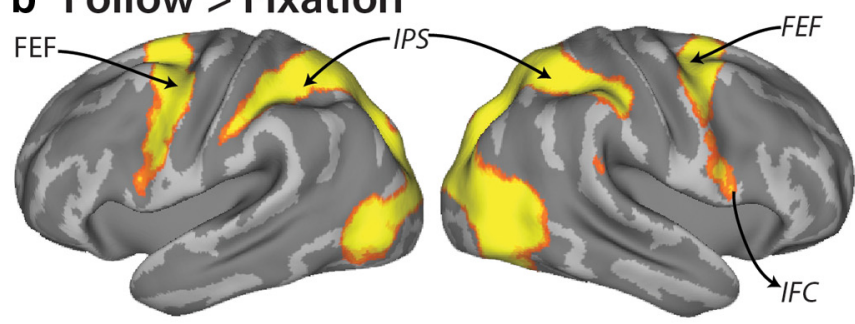

c Noncompensated $>$ Follow
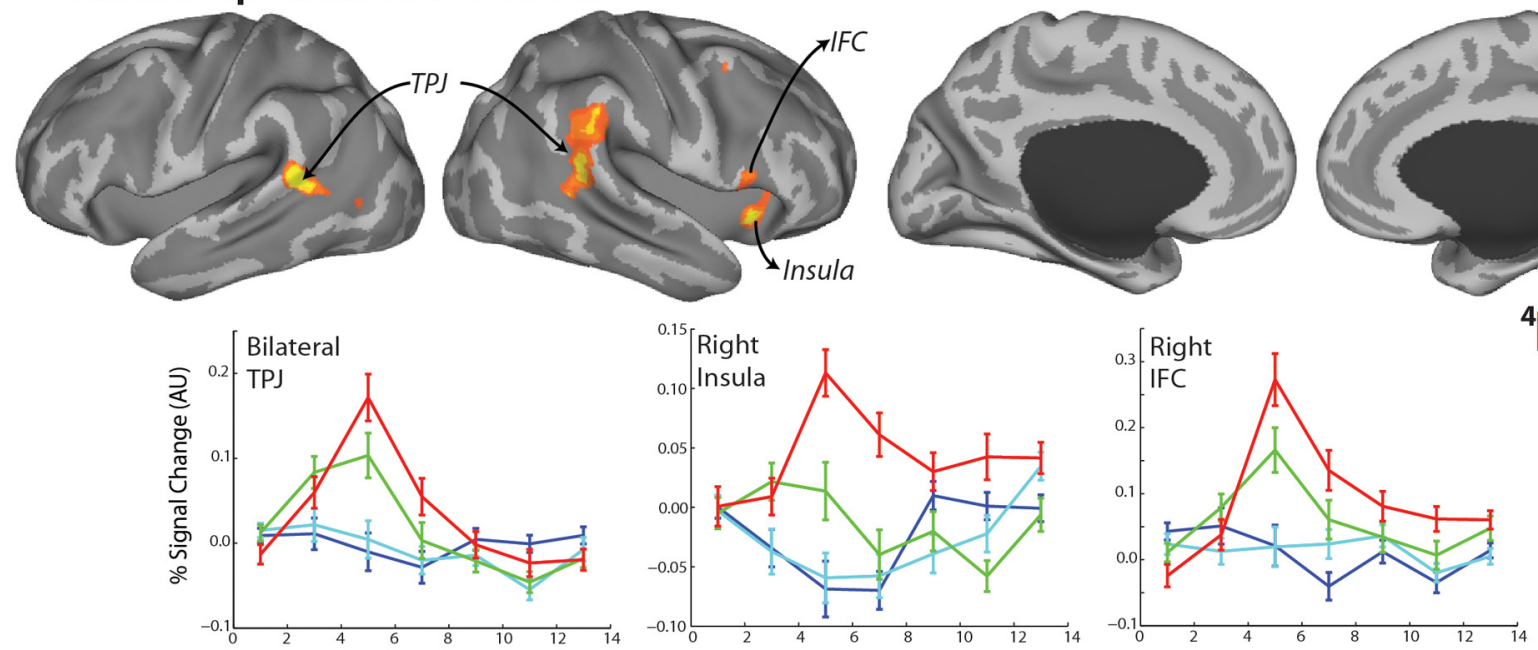

Time from array onset (s)
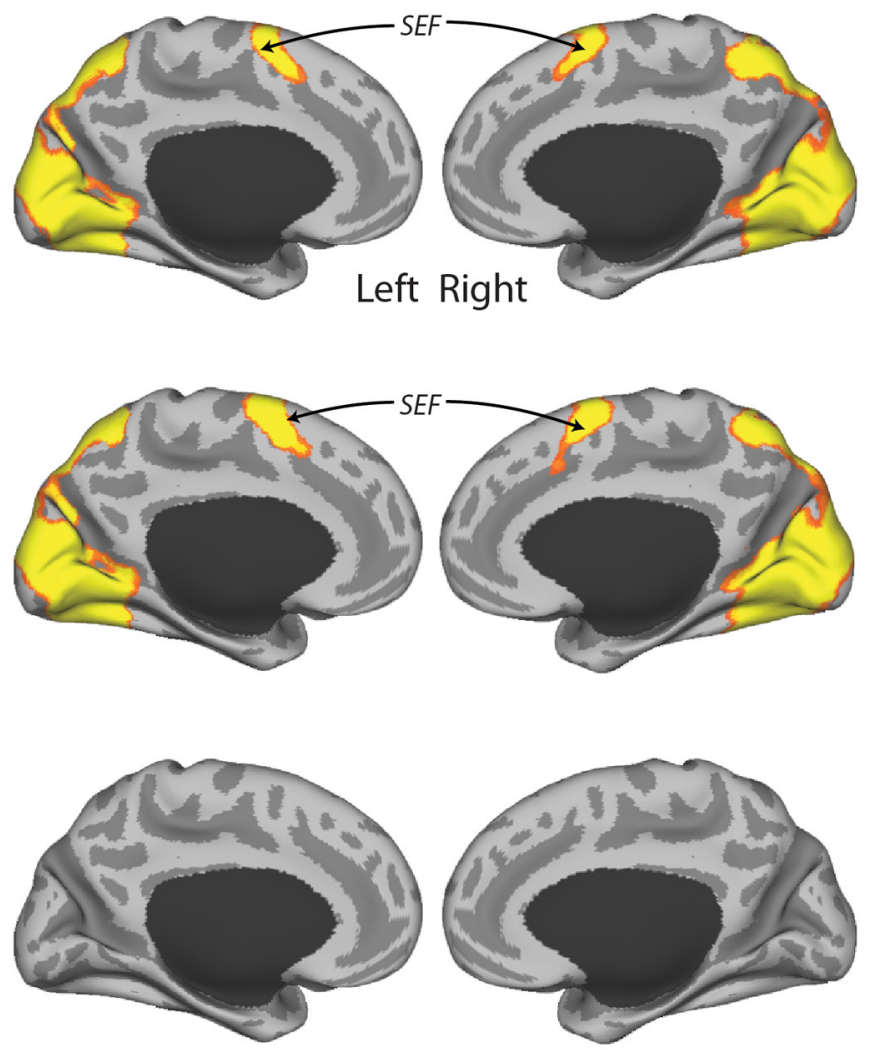

${ }^{4.1}{ }_{\text {t-value }} 6.0$

-No-step Compensated - Noncompensated CFollow

Figure 8. BOLD activation that is greater for noncompensated than follow trials. Cortical activation that is greater for noncompensated trials versus fixation (a), follow trials versus fixation ( $\boldsymbol{b})$, and noncompensated versus follow trials (c) was rendered onto an MNI-normalized inflated surface. Activation is displayed at an uncorrected $p<0.0001$. Clusters that met significance at an FWE-corrected $p<0.05$ are displayed in Table 1. Group event-related time courses (bottom) were calculated for each trial type within a 3 mm sphere centered on the maximally activated voxel in TPJ, right insula, and right IFC. For TPJ, time courses were averaged across right and left hemispheres. Error bars indicate SEM.

however, increased activation may also be due to additive visual and motor activity.

In other regions, activation was present during compensated but not no-step trials, suggesting a role for these areas in saccade inhibition and redirection, attention to the target step, and/or conflict monitoring. One region that showed this pattern was SEF. Although SEF activation was observed on no-step trials, a more anterior region of SEF (pre-SEF; Grosbras et al., 2001) showed activation on compensated but not no-step trials. These data provide compelling evidence for functional specificity within the SMC (Zhang et al., 2012), with increasingly complex action planning represented rostrally (Nachev et al., 2005; Nachev et al., 2008; Neggers et al., 2012). With regard to the role of SMC in response cancellation, nonhuman primate and human studies have yielded somewhat different conclusions, potentially due to differences in species, response effector, and/or methodology. Consistent with our findings, previous human studies sup- port a role of the pre-SMA in reactively stopping (Nachev et al., 2007; Sharp et al., 2010; Swick et al., 2011; Hsu et al., 2011; Hu and Li, 2012) and changing (Nachev et al., 2005) actions, particularly anterior pre-SMA (Li et al., 2006; Chao et al., 2009; Duann et al., 2009), possibly by exerting an influence over M1 via basal ganglia (Duann et al., 2009; Zandbelt et al., 2013b). Neurophysiological recordings during correctly cancelled saccades also show modulation of SEF neurons; however, modulation typically occurs too late to implement movement control directly (Stuphorn et al., 2000; Emeric et al., 2010; Scangos and Stuphorn, 2010). Rather, SEF is sensitive to response conflict and errors and implements context-based behavioral adjustments (Schall and Boucher, 2007; Sharika et al., 2013). The temporal resolution of fMRI limits our conclusions regarding the precise nature of preSEF activation. The relationship between error saccade amplitude and SEF activation, however, sheds additional light on its role in action control. Noncompensated saccades were shorter 
a

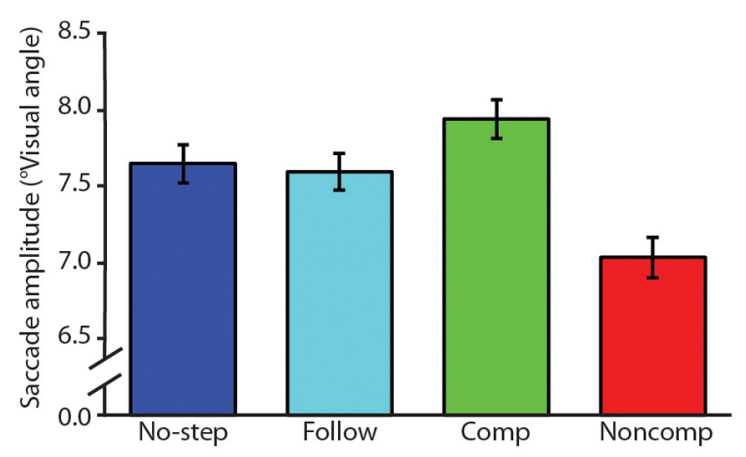

b

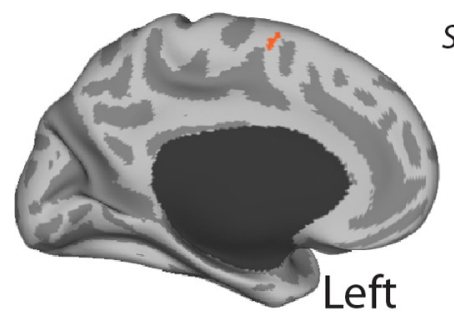

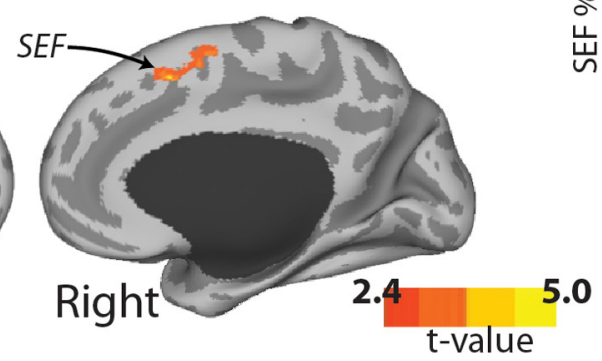

C

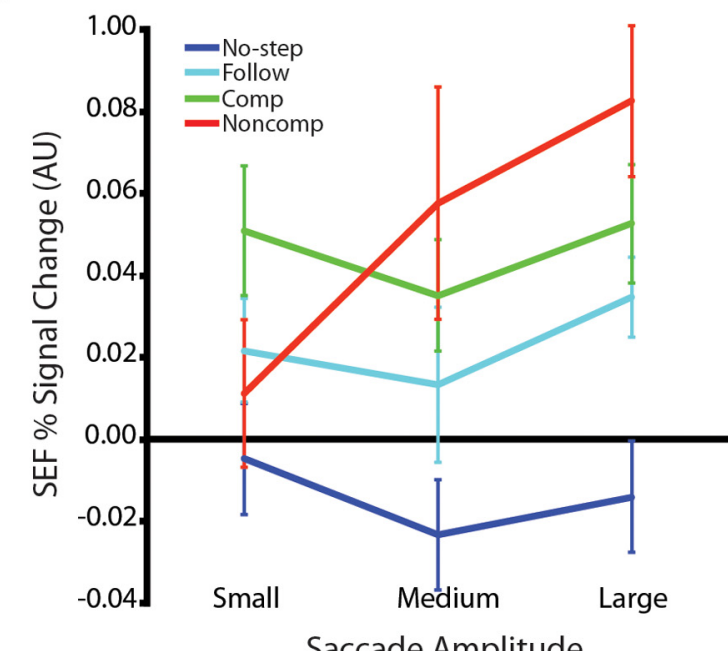

Saccade Amplitude

Figure 9. Error saccade amplitude parametric analysis. $\boldsymbol{a}$, Mean saccade amplitudes for all four trial types were averaged across subjects. Noncompensated saccades were shorter than all other trial types. Error bars indicate SEM. $\boldsymbol{b}$, Regions of MFC that were linearly related to trial-by-trial variations in noncompensated saccade amplitude were rendered onto an MNI-normalized inflated surface. In these regions, larger error saccade amplitudes yielded larger MFC activation. $c$, This relationship between MFC activation and saccade amplitude was only observed for noncompensated trials. To illustrate this finding, saccade amplitudes for each of the four trial types were binned into three equal bins for each subject: small, medium, and large. Percent signal change in a 3 mm sphere centered on the MFC voxel that showed a maximal effect of saccade amplitude on BOLD activation during noncompensated trials was calculated for each of the three bins in each of the four trial types and averaged across participants. Error bars indicate SEM.

than correct saccades, suggesting that inhibitory processes have influence over error saccade movement dynamics. If SEF has a direct role in inhibition, then one would expect greater activation predicting shorter error saccades, reflecting a greater behavioral effects of inhibition. We observed, however, that SEF activation was associated with larger error saccades, suggesting a prominent role in monitoring rather than directly controlling movement.

We also observed right IFC activation during compensated, but not no-step, trials, which is consistent with previous studies (Aron et al., 2004; Leung and Cai, 2007; Cai et al., 2014). The specific role of the right IFC in action control is a topic of lively debate (Schall and Godlove, 2012; Aron et al., 2014). Initially proposed to have a direct role in inhibition via basal ganglia connections (Nambu et al., 2002; Aron and Poldrack, 2006), it was more recently suggested to play an indirect role in inhibition by orienting attention to the stop signal (Duann et al., 2009; Hampshire et al., 2010; Sharp et al., 2010). Because we do not control for attentional capture, our data cannot distinguish between these hypotheses.

Subcortically, we observed activation in caudate, thalamus, and SC that was greater on compensated trials without significant no-step trial activation. Basal ganglia influences movement activity in SC directly and in FEF via thalamus (for review, see Hikosaka et al., 2000). Specifically, the indirect pathway, projecting from striatum to the substantia nigra pars reticulata (SNpr) via globus pallidus and subthalamic nucleus, inhibits movementrelated activity. Neurophysiology (Watanabe and Munoz, 2010, 2013) and fMRI studies (Vink et al., 2005; Ford et al., 2009; Zandbelt and Vink, 2010; Zandbelt et al., 2013a) have shown that striatal activity is modulated by context and have established a role for the striatum in anticipating the need to inhibit, or proactive inhibition. These fMRI studies also hint at a role of the stria- tum in reactive manual inhibition (Zandbelt and Vink, 2010; Jahfari et al., 2011; Zandbelt et al., 2013b). Our results suggest a role of the striatum and direct projection sites of the basal ganglia in reactive control of gaze. Attesting further to the caudate's role in inhibition, faster TSRT was related to greater caudate activation on compensated versus no-step trials (Li et al., 2008).

Because the precise timing of striatal activition is unknown, it is unclear whether caudate activation indicates a rapid attempt to inhibit movement activity in FEF and SC after the target step or dynamic alterations priming the oculomotor system toward automatic or controlled action. Further, a specific role of the indirect pathway in movement inhibition has been challenged by recent rodent studies that refute such a dichotomy between direct and indirect pathways in movement initiation and inhibition (Cui et al., 2013) and suggest that stopping is implemented via a race between direct and indirect pathway signals toward the SNpr (Schmidt et al., 2013). This has yet to be tested in primates and, unfortunately, the coarse temporal resolution of fMRI and spatial resolution of our functional scans limits our speculations on such a race within the basal ganglia and the specific role of smaller subcortical nuclei.

\section{Monitoring errors}

To examine brain regions involved in detecting and monitoring errors, we compared noncompensated trials with follow trials. Surprisingly, greater MFC activation was not observed despite ample data highlighting its role in error monitoring (for review, see Falkenstein, 2004; Schall and Boucher, 2007). There are several potential reasons. First, error and correct trials were matched on motor output, contrary to many previous fMRI studies. Noncompensated saccades are almost always corrected, so we compared them with follow trials in which two saccades were also 
executed. The absence of MFC activation differences between these two trials suggests that the error-related MFC BOLD response might be at least partly related to sequential movement planning involved in programming the corrective response (Nachev et al., 2008; Hu and Walker, 2011). Indeed, larger errorrelated event-related potentials are observed for corrected versus uncorrected errors (Gehring et al., 1993). Second, we adjusted TSDs to ensure a $50 \%$ error rate. Previous studies report that error-related MFC activity decreases as the motivational significance of errors decreases (Gehring et al., 1993) and error likelihood increases (Jessup et al., 2010). Therefore, the absence of MFC activation differences for noncompensated versus follow trials might be due to the errors being common, and thus less motivationally salient, in this task.

Notably, we observed that pre-SEF activation scaled with error saccade amplitude - in other words, with how wrong the response was. Larger errors might result in heightened error awareness or, more generally, a greater need for cognitive control that is represented by pre-SEF activation. In addition, activation in bilateral TPJ and right anterior insula and IFC was greater on noncompensated trials, which is consistent with prior studies (Ullsperger and von Cramon, 2004; Ramautar et al., 2006; Ullsperger et al., 2010). These regions overlap significantly with a network implicated in directing attention to salient or unexpected events (for review, see Corbetta and Shulman, 2002); therefore, activation might reflect error-specific processing or a more general orienting response.

\section{Summary and implications}

To summarize, in the present study, we observed for the first time in humans a cortico-thalamo-striatal network that was involved in rapidly inhibiting and changing an eye movement. Further, we report that MFC activation scales with the size of an error. These data lend new evidence for a role of the striatum in reactive saccade control and further clarify the role of MFC in action inhibition and performance monitoring. These results and their strong correspondence with primate neurophysiology have implications for understanding mechanisms of abnormal action control in neuropsychiatric disorders (Armstrong and Munoz, 2003; Joti et al., 2007; Thakkar et al., 2011).

\section{References}

Alexander GE, Crutcher MD, DeLong MR (1990) Basal gangliathalamocortical circuits: parallel substrates for motor, oculomotor, "prefrontal" and "limbic" functions. Prog Brain Res 85:119-146. Medline

Armstrong IT, Munoz DP (2003) Inhibitory control of eye movements during oculomotor countermanding in adults with attention-deficit hyperactivity disorder. Exp Brain Res 152:444-452. CrossRef Medline

Aron AR (2011) From reactive to proactive and selective control: developing a richer model for stopping inappropriate responses. Biol Psychiatry 69:e55-68. CrossRef Medline

Aron AR, Poldrack RA (2006) Cortical and subcortical contributions to stop signal response inhibition: role of the subthalamic nucleus. J Neurosci 26:2424-2433. CrossRef Medline

Aron AR, Robbins TW, Poldrack RA (2004) Inhibition and the right inferior frontal cortex. Trends Cogn Sci 8:170-177. CrossRef Medline

Aron AR, Robbins TW, Poldrack RA (2014) Inhitbion and the right inferior frontal cortex: one decade on. Trends Cogn Sci 18:177-185. CrossRef Medline

Ashburner J, Friston KJ (2005) Unified segmentation. Neuroimage 26:839851. CrossRef Medline

Boucher L, Palmeri TJ, Logan GD, Schall JD (2007) Inhibitory control in mind and brain: an interactive race model of countermanding saccades. Psychol Rev 114:376-397. CrossRef Medline

Cai W, Cannistraci CJ, Gore JC, Leung HC (2014) Sensorimotorindependent prefrontal activity during response inhibition. Hum Brain Mapp 35:2119-2136. CrossRef Medline
Camalier CR, Gotler A, Murthy A, Thompson KG, Logan GD, Palmeri TJ, Schall JD (2007) Dynamics of saccade target selection: race model analysis of double step and search step saccade production in human and macaque. Vision Res 47:2187-2211. CrossRef Medline

Chamberlain SR, Sahakian BJ (2007) The neuropsychiatry of impulsivity. Curr Opin Psychiatry 20:255-261. Medline

Chambers CD, Garavan H, Bellgrove MA (2009) Insights into the neural basis of response inhibition from cognitive and clinical neuroscience. Neurosci Biobehav Rev 33:631-646. CrossRef Medline

Chao HH, Luo X, Chang JL, Li CS (2009) Activation of the presupplementary motor area but not inferior prefrontal cortex in association with short stop signal reaction time- an intra-subject analysis. BMC Neuroscience 10:75. CrossRef Medline

Congdon E, Mumford JA, Cohen JR, Galvan A, Canli T, Poldrack RA (2012) Measurement and reliability of response inhibition. Front Psychol 3:37. CrossRef Medline

Corbetta M, Shulman GL (2002) Control of goal-directed and stimulusdriven attention in the brain. Nat Rev Neurosci 3:201-215. CrossRef Medline

Cui G, Jun SB, Jin X, Pham MD, Vogel SS, Lovinger DM, Costa RM (2013) Concurrent activation of striatal direct and indirect pathways during action initiation. Nature 494:238-242. CrossRef Medline

Curtis CE, Cole MW, Rao VY, D'Esposito M (2005) Canceling planned action: an FMRI study of countermanding saccades. Cereb Cortex 15:12811289. CrossRef Medline

Dejardin S, Dubois S, Bodart JM, Schiltz C, Delinte A, Michel C, Roucoux A, Crommelinck M (1998) PET study of human voluntary saccadic eye movements in darkness: effect of task repetition on the activation pattern. Eur J Neurosci 10:2328-2336. CrossRef Medline

Duann JR, Ide JS, Luo X, Li CS (2009) Functional connectivity deliniates distinct roles of the inferior frontal cortex and presupplementary motor area in stop signal inhibition. J Neurosci 29:10171-10179. CrossRef Medline

Emeric EE, Leslie M, Pouget P, Schall JD (2010) Performance monitoring local field potentials in the medial frontal cortex of primates: Supplementary eye field. J Neurophysiol 104:1523-1537. CrossRef Medline

Falkenstein M (2004) ERP correlates of erroneous performance. In: Errors, conflicts, and the brain: current opinions on performance monitoring (Ullsperger M, Falkenstein M, eds), pp 5-14. Leipzig: Max Planck Institute of Cognitive Neuroscience.

Ford KA, Gati JS, Menon RS, Everling S (2009) BOLD fMRI activation for anti-saccades in nonhuman primates. Neuroimage 45:470-476. CrossRef Medline

Gehring WJ, Goss B, Coles MGH, Meyer DE, Donchin E (1993) A neural system for error detection and compensation. Psychol Sci 4:385-390. CrossRef

Glover GH, Li TQ, Ress D (2000) Image-based method for retrospective correction of physiological motion effects in fMRI: RETROICOR. Magn Reson Med 44:162-167. CrossRef Medline

Grosbras MH, Leonards U, Lobel E, Poline JB, LeBihan D, Berthoz A (2001) Human cortical networks for new and familiar sequences of saccades. Cereb Cortex 11:936-945. CrossRef Medline

Hampshire A, Chamberlain SR, Monti MM, Duncan J, Owen AM (2010) The role of the right inferior frontal gyrus: inhibition and attentional control. Neuroimage 50:1313-1319. CrossRef Medline

Hanes DP, Patterson WF 2nd, Schall JD (1998) Role of frontal eye fields in countermanding saccades: visual, movement, and fixation activity. J Neurophysiol 79:817-834. Medline

Hikosaka O, Takikawa Y, Kawagoe R (2000) Role of the basal ganglia in the control of purposive saccadic eye movements. Physiol Rev 80:953-978. Medline

Holm S (1979) A simple sequentially rejective multiple test procedure. Scandinavian Journal of Statistics 6:65-70.

Hsu TY, Tseng LY, Yu JX, Kuo WJ, Hung DL, Tzeng OJ, Walsh V, Muggleton NG, Juan CH (2011) Modulating inhibitory control with direct current stimulation of the superior medial frontal cortex. Neuroimage 56:22492257. CrossRef Medline

Hu S, Li CS (2012) Neural processes of preparatory control for stop signal inhibition. Hum Brain Mapp 33:2785-2796. CrossRef Medline

Hu Y, Walker R (2011) The neural basis of parallel saccade programming: an fMRI study. J Cogn Neurosci 23:3669-3680. CrossRef Medline

Ito S, Stuphorn V, Brown JW, Schall JD (2003) Performance monitoring by 
the anterior cingulate cortex during saccade countermanding. Science 302:120-122. CrossRef Medline

Jahfari S, Waldorp L, van den Wildenberg WP, Scholte HS, Ridderinkhof KR, Forstmann BU (2011) Effective connectivity reveals important roles for both the hyperdirect (fronto-subthalamic) and the indirect (frontostriatal-pallidal) fronto-basal ganglia pathways during response inhibition. J Neurosci 31:6891-6899. CrossRef Medline

Jessup RK, Busemeyer JR, Brown JW (2010) Error effects in anterior cingulate cortex reverse when error likelihood is high. J Neurosci 30:3467-3472. CrossRef Medline

Joti P, Kulashekhar S, Behari M, Murthy A (2007) Impaired inhibitory oculomotor control in patients with Parkinson's disease. Exp Brain Res 177:447-457. CrossRef Medline

Krebs RM, Woldorff MG, Tempelmann C, Bodammer N, Noesselt T, Boehler CN, Scheich H, Hopf JM, Duzel E, Heinze HJ, Schoenfeld MA (2010) High-field FMRI reveals brain activation patterns underlying saccade execution in the human superior colliculus. PLoS One 5:e8691. CrossRef Medline

Leung HC, Cai W (2007) Common and differential ventrolateral prefrontal activity during inhibition of hand and eye movements. J Neurosci 27: 9893-9900. CrossRef Medline

Li CS, Huang C, Constable RT, Sinha R (2006) Imaging response inhibition in a stop-signal task: neural correlates independent of signal monitoring and post-response processing. J Neurosci 26:186-192. CrossRef Medline

Li CS, Yan P, Sinha R, Lee TW (2008) Subcortical processes of motor response inhibition during a stop signal task. Neuroimage 41:1352-1363. CrossRef Medline

Logan GD, Cowan WB (1984) On the ability to inhibit thought and action: A theory of an act of control. Psychol Rev 91:295-327. CrossRef

Murthy A, Ray S, Shorter SM, Priddy EG, Schall JD, Thompson KG (2007) Frontal eye field contributions to rapid corrective saccades. J Neurophysiol 97:1457-1469. Medline

Murthy A, Ray S, Shorter SM, Schall JD, Thompson KG (2009) Neural control of visual search by frontal eye field: effects of unexpected target displacement on visual selection and saccade preparation. J Neurophysiol 101:2485-2506. Medline

Nachev P, Rees G, Parton A, Kennard C, Husain M (2005) Volition and conflict in human medial frontal cortex. Curr Biol 15:122-128. CrossRef Medline

Nachev P, Wydell H, O’Neill K, Husain M, Kennard C (2007) The role of the pre-supplementary motor area in the control of action. Neuroimage 36: T155-T163. CrossRef Medline

Nachev P, Kennard C, Husain M (2008) Functional role of the supplementary and pre-supplementary motor areas. Nat Rev Neurosci 9:856-869. CrossRef Medline

Nambu A, Tokuno H, Takada M (2002) Functional significance of the cortico-subthalamo-pallidal 'hyperdirect' pathway. Neurosci Res 43:111117. CrossRef Medline

Neggers SF, Diepen RM, Zandbelt BB, Vink M, Mandl RC, Gutteling TP (2012) A functional and structural investigation of the human frontobasal volitional saccade network. PLoS One 7:e29517. CrossRef Medline

Paré M, Hanes DP (2003) Controlled movement processing: superior colliculus activity associated with countermanded saccades. J Neurosci 23: 6480-6489. Medline

Ramakrishnan A, Sureshbabu R, Murthy A (2012) Understanding how the brain changes its mind: microstimulation in the macaque frontal eye field reveals how saccade plans are changed. J Neurosci 32:4457-4472. CrossRef Medline

Ramautar JR, Slagter HA, Kok A, Ridderinkhof KR (2006) Probability effects in the stop-signal paradigm: the insula and the significance of failed inhibition. Brain Res 1105:143-154. CrossRef Medline

Reinhart RM, Carlisle NB, Kang MS, Woodman GF (2012) Event-related potentials elicited by errors during the stop-signal task. II: human effector-specific error responses. J Neurophysiol 107:2794-2807. CrossRef Medline

Salinas E, Stanford TR (2013) The countermanding task revisited: fast stim- ulus detection is a key determinant of psychophysical performance. J Neurosci 33:5668-5685. CrossRef Medline

Scangos KW, Stuphorn V (2010) Medial frontal cortex motivates but does not control movement initiation in the countermanding task. J Neurosci 30:1968-1982. CrossRef Medline

Schall JD, Boucher L (2007) Executive control of gaze by the frontal lobes. Cogn Affect Behav Neurosci 7:396-412. CrossRef Medline

Schall JD, Godlove DC (2012) Current advances and pressing problems in studies of stopping. Curr Opin Neurobiol 22:1012-1021. CrossRef Medline

Schmidt R, Leventhal DK, Mallet N, Chen F, Berke JD (2013) Canceling actions involves a race between basal ganglia pathways. Nat Neurosci 16:1118-1124. CrossRef Medline

Sharika KM, Neggers SFW, Gutteling TP, van der Stigchel S, Dijkerman HC, Murthy A (2013) Proactive control of sequential saccades in the human supplementary eye field, Proc Natl Acad Sci U S A 110:E1311-E1320. CrossRef Medline

Sharp DJ, Bonnelle V, De Boissezon X, Beckmann CF, James SG, Patel MC, Mehta MA (2010) Distinct frontal systems for response inhibition, attentional capture, and error processing. Proc Natl Acad Sci U S A 107: 6106-6111. CrossRef Medline

Stuphorn V, Taylor TL, Schall JD (2000) Performance monitoring by the supplementary eye field. Nature 408:857-860. CrossRef Medline

Swick D, Ashley V, Turken U (2011) Are the neural correlates of stopping and not going identical? Quantitative meta-analysis of two response inhibition tasks. Neuroimage 56:1655-1665. CrossRef Medline

Thakkar KN, Schall JD, Boucher L, Logan G, Park S (2011) Response inhibition and response monitoring in a saccadic countermanding task in schizophrenia. Biol Psychiatry 69:55-62. CrossRef Medline

Tzourio-Mazoyer N, Landeau B, Papathanassiou D, Crivello F, Etard O, Delcroix N, Mazoyer B, Joliot M (2002) Automated anatomical labeling of activations in SPM using a macroscopic anatomical parcellation of the MNI MRI single-subject brain. Neuroimage 15:273-289. CrossRef Medline

Ullsperger M, von Cramon DY (2004) Neuroimaging of performance monitoring: error detection and beyond. Cortex 40:593-604. CrossRef Medline

Ullsperger M, Harsay HA, Wessel JR, Ridderinkhof KR (2010) Conscious perception of errors and its relation to the anterior insula. Brain Struct Funct 214:629-643. CrossRef Medline

Van der Stigchel S, Nijboer TCW (2011) The global effect: what determines where the eyes land? Journal of Eye Movement Research 4:1-13.

Verbruggen F, Chambers CD, Logan GD (2013) Fictitious inhibitory differences: how skewness and slowing distort the estimation of stopping latencies. Psychol Sci 24:352-362. CrossRef Medline

Vink M, Kahn RS, Raemaekers M, van den Heuvel M, Boersma M, Ramsey NF (2005) Function of striatum beyond inhibition and execution of motor responses. Hum Brain Mapp 25:336-344. CrossRef Medline

Watanabe M, Munoz DP (2010) Saccade suppression by electrical microstimulation in monkey caudate nucleus. J Neurosci 30:2700-2709. CrossRef Medline

Watanabe M, Munoz DP (2013) Effects of caudate microstimulation on spontaneous and purposive saccades. J Neurophysiol 110:334-343. CrossRef Medline

Zandbelt BB, Vink M (2010) On the role of the striatum in response inhibition. PLoS One 5:e13848. CrossRef Medline

Zandbelt BB, Bloemendaal M, Neggers SF, Kahn RS, Vink M (2013a) Expectations and violations: Delineating the neural network of proactive inhibitory control. Hum Brain Mapp 34:2015-2024. CrossRef Medline

Zandbelt BB, Bloemendaal M, Hoogendam JM, Kahn RS, Vink M (2013b) Transcranial magnetic stimulation and functional MRI reveal cortical and subcortical interactions during stop-signal response inhibition. J Cogn Neurosci 25:157-174. CrossRef Medline

Zhang S, Ide JS, Li CS (2012) Resting-steate connectivity of the medial superior frontal cortex. Cereb Cortex 22:99-111. CrossRef Medline 